HEALTHCARE DELIVERY

\title{
Curatorship applications: The role of neuropsychology
}

\author{
K L Rice, MPsych; M L Hendricks, MA (Psychology) \\ Department of Psychology, Faculty of Arts and Social Sciences, Stellenbosch University and Stikland Hospital, Cape Town, South Africa
}

Corresponding author: K L Rice (kirstyricect@gmail.com, kirsten.rice@westerncape.gov.za)

This article highlights ethical issues that may arise in the relationship between curatorship applications and neuropsychology. In South Africa (SA), curatorship applications for the elderly diagnosed with dementia require substantiation from two medical professionals, one of whom should be a practising psychiatrist deemed competent to provide this. Concurrently, there is often a request for a psychologist to conduct a neuropsychological assessment and to produce a relevant report. The process may result in ethical issues at various stages of the assessment. The balance between protecting the patient's rights v. freedom of autonomy becomes a central issue. Psychiatrists and psychologists are cautioned to adhere to best practices throughout the assessment, maintaining a critical and reflective stance. The limitations of cognitive assessment as a predictor of functionality should be considered. Furthermore, neuropsychological training in SA differs across institutions, resulting in variable practitioner competency. 'Competency' itself is an ambiguous legal term that may be interpreted variably. This article outlines the definitions and requirements of the curatorship process, as well as the role and limitations of neuropsychology, with emphasis on the ethical dilemmas that may arise.

S Afr Med J 2022;112(3):209-213. https://doi.org/10.7196/SAMJ.2022.v112i3.16215

Living in an ageing society, the phenomenon of cognitive decline is likely to increase in coming years. ${ }^{[1,2]}$ The World Health Organization (WHO) documented that in 2019, the number of people aged $\geq 60$ years was 1 billion. ${ }^{[3]}$ This number is projected to increase to 1.4 billion by 2030 and 2.1 billion by $2050 .{ }^{[3]}$ The WHO also estimates that 55 million people live with dementia worldwide, with an expected increase of 10 million per year. ${ }^{[4]}$ The diagnosis of dementia is also becoming more frequent. ${ }^{[1,2]}$ Neurocognitive deficits associated with COVID-19 $9^{[5]}$ and the increased prevalence of HIVrelated dementia may contribute to the increase in dementia cases, including young-onset dementia, ${ }^{[6]}$ therefore potentially decreasing the age of persons requiring curatorship. Consequently, questions of legal competency may therefore arise more often..$^{[7,8]}$

A diagnosis of dementia may lead to curatorship application. ${ }^{[8]}$ Neuropsychological assessment is increasingly used for civil (and criminal) matters, including capacity assessments. ${ }^{[7]}$ Neuropsychology assessments include applications for curatorship for the elderly, particularly when a diagnosis of a neurocognitive disorder (dementia) is made ${ }^{[9]}$ This article focuses exclusively on this population, as there are often issues related to their assets that necessitate a curatorship application. The article excludes detailing matters regarding minors or intellectual disability.

Curatorship is a legal process relying on clinical information to be activated, bringing about medicolegal and ethical challenges. ${ }^{[8,10,11]}$ While it is an increasingly routine request made of psychologists, ${ }^{[7,9,12]}$ a high level of ethical awareness is encouraged among all mental health professionals. ${ }^{[13,14]}$ Ethical awareness in these cases is important, as the role of neuropsychology in this process may be inconsistent ${ }^{[13,14]}$ and is often scrutinised by practitioners, international working groups, and academics in the field. ${ }^{[12-15]}$ Similarly, the efficacy of some neuropsychological tests as an indicator of functioning has been questioned. ${ }^{[1,16,17]}$

Several core ethical practices outlined by $\mathrm{SA}$ law ${ }^{[18-23]}$ as well as the Health Professions Council of South Africa (HPCSA) ${ }^{[24,25]}$ are relevant to the curatorship process. Clinicians are cautioned regarding the balance between providing essential clinical care to the vulnerable and the protection of patient rights..$^{[1,11,26,27]}$ In this article, the definitions associated with curatorship in SA are provided, as are the requirements, associated processes and consequent implications. The limitations and role of neuropsychology related to ethical aspects of the curatorship process are outlined to assist in informing best clinical practice.

\section{Definition of competency and curatorship}

Questions of curatorship typically arise when a person's lack of competency to manage their own affairs is raised by either healthcare practitioners or family members. ${ }^{[1,9,26]}$ 'Competency' is a legal concept, used as an umbrella term that broadly refers to a person's ability to appreciate the nature, purpose and consequences of their decisions. ${ }^{[27-29]}$ 'Capacity' is considered a clinical concept that clinicians may report on. ${ }^{[1]}$ In neuropsychology, an important aspect informing capacity is executive functioning, among other cognitive functions. Executive functioning deficits specifically include the ability to plan, make decisions, utilise working memory, correct errors, respond to feedback, override habits, inhibit behaviour and utilise mental flexibility, all of which are relevant to decision-making capacities. ${ }^{[30]}$ Decisions related to competency typically focused on in the literature concern medical treatment, financial management, and/or aspects of personal wellbeing. ${ }^{[1,8,9]}$ Intact executive functioning is therefore implicated in the ability to meet the demands of daily life. ${ }^{[30,31]}$ When a person is found to be incompetent (and therefore likely to have executive function deficits), any legal action taken by the person is considered void under SA law. ${ }^{[8]}$

A systematic review indicated that legal orders supporting curatorship occur $84-100 \%$ of the time during curatorship applications, ${ }^{[29]}$ and the application is rarely dismissed. ${ }^{[29]}$ The fact that curatorship applications are rarely overturned is significant, as the decision made regarding competency may result in infringements of the right to freedom and equality, impacting on the person's 
ability to exercise their fundamental human rights. ${ }^{[18]}$ The lack of autonomy brought about by a curatorship ruling can be problematic, particularly in cases of milder cases of dementia where a person may have some degree of impairment but still maintain relative decisionmaking competency.

A curator is described as 'one who is authorised to act under letters of curatorship granted or signed and sealed by a Master' (as stated in the Administration of Estates Act 66 of 1965, ${ }^{[23]}$ section 1). Curatorship operates in three domains: a curator bonis is legally appointed via the courts and receives jurisdiction over a person's estate, while a curator personae is tasked with the management of the patient's wellbeing and day-to-day living, including medical decisions. ${ }^{[27]} \mathrm{A}$ curator ad litem manages all legal proceedings on behalf of the patient. A curator may manage the estate of a person and/or matters related to their wellbeing, such as medical decisionmaking or matters of accommodation. If a curatorship application succeeds, a person's independent living is severely restricted from a legal standpoint; the nature of dementia places inherent restrictions on functional abilities in its own right. ${ }^{[30]}$

Curatorship must be differentiated from 'administration'. Both 'curator' and 'administrator' are referenced in the Administration of Estates Act ${ }^{[23]}$ and the Mental Health Care Act 17 of 2002. ${ }^{[21]}$ It is not explicitly referred to in Act 13 of 2006, the Older Person's Act, ${ }^{[22]}$ yet has definitive implications for the elderly. Either a curator or an administrator is appointed when a person is found to be incompetent in terms of making decisions. An administrator is described 'as a person appointed ... to care for and administer the property of a mentally ill person' (as stated by the Mental Health Care Act ${ }^{[21]}$ ). An administrator can only manage a person's property, while decisions related to personhood remain intact. ${ }^{[8]}$ For example, a person experiencing mental illness that has a variable but not necessarily progressive course, such as the neurocognitive deficits associated with bipolar mood disorder, is best managed under the process of an administrator. Curatorship may affect personhood and property, and it is also more permanent; the nature and the course of disease are often predicted to be progressive, and a profile of deterioration is predicted.

\section{Requilirements and processes for curatorship application}

Competency that is questioned because of a person's mental state is managed in accordance with the Mental Health Care Act, ${ }^{[21]}$ chapter VIII. An application for a curator is indicated when a person is diagnosed with a severe mental illness (which includes diagnoses of dementia as well as organic conditions) or intellectual disability. ${ }^{[8]}$ Rule 57 of the Uniform Rules for the High Court stipulates that for the application to be made, a diagnosis must be made by an authorised mental healthcare practitioner. ${ }^{[8]}$ The diagnosis requires substantiated medical certificates or reports clearly indicating that incompetency is a direct result of the mental illness, which may include a neuropsychological report produced by a clinical or neuropsychologist. ${ }^{[8,21]}$

According to Rule 57, any person over the age of 18 years may put forward an application for curatorship when competency is questioned due to mental illness or disability. The application requires an affidavit from the applicant and the support of two medical practitioners, one of whom must be an alienist, i.e. a competent psychiatrist not known to the patient. ${ }^{[28]}$ The affidavits of the two medical practitioners should state the nature and duration of and reasons for the application, and declare that they have no personal interest or relationship to the patient.
Medical practitioners at this point may seek the support of a psychologist, requesting neuropsychological assessment. The aim of the assessment is generally to ascertain the state of the patient's illness, which has implications for assessment of competency. ${ }^{[29]}$ While this is often a recommended and necessary step to support medical decision-making, the role of neuropsychology needs to be considered carefully. ${ }^{[2]}$

\section{Review of patient rights}

The curatorship process as well as the appointment of a curator demands the consideration of several SA laws. While the points below are not exhaustive, they highlight pertinent ethical and legal issues related to curatorship, emphasised in legislation.

Under the SA Constitution ${ }^{[18]}$ (chapter 2, the Bill of Rights), basic human rights such as equality (section 9), dignity (section 10) and freedom (section 12) need to be held in mind. In accordance with the National Health Act 61 of $2003^{[19]}$ (chapter 2), aspects related to autonomy such as informed consent (section 7), as well as the need for active participation (section 8 ) in healthcare decisions, are at play. ${ }^{[17]}$ These rights are in line with the Health Professions Act 56 of 1974, ${ }^{[20]}$ annexure 12, in which respect (section 10), informed consent (section 11), issues of discrimination (section 12), avoiding harm (section 15), and confidentiality (sections 24, 25 and 26) need to be considered. The Mental Health Care Act ${ }^{[21]}$ outlines similar guidelines, and highlights the need for proportionate care (section 8.3).

The practitioner also needs to be conscious of the patient's right to autonomy, integrity and confidentiality, as stipulated by the HPCSA's ethical guidelines. ${ }^{[24,25]}$ Healthcare practitioners need to be cognisant of potential conflicts in these guidelines. For example, the rules outlined in annexure 12 of the Health Professions Act, ${ }^{[20]}$ section 46.3, allow omission of written informed consent when capacity is the question at hand, yet the National Health Act ${ }^{[19]}$ states that treatment cannot proceed without consent. The severity of a patient's illness evokes the extent and gravity of ethical protection the patient requires.

\section{Implications of curatorship application for the patient}

In each curatorship case, the often progressive impairment of functioning ${ }^{[31]}$ and associated risks have to be weighed against the concomitant loss of autonomy, particularly when the applications are approved. ${ }^{[2]}$ Autonomy is infringed upon by the appointment of a curator or administrator, and while the appointee is mandated to act in the person's best interest, this is perceived to be more complicated in practice ${ }^{[8]}$ For example, a curator appointed may not have sufficient expertise on the subtleties of the nature and course of dementia.

The cost to the individual on whose behalf curatorship is sought is immense, as the person no longer has independent access to: (i) choices facilitated by financial freedom, including day-to-day spending, investments, and decisions regarding property or trading shares; (ii) decisions regarding personal welfare, such as where to live or choice of accommodation; and (iii) choices regarding medical treatment, including refusal.

The law does not allow for flexibility in its appointment of a third party: although recommendations have been made regarding tailored or partial curatorship, ${ }^{[8,10]}$ currently there is no accommodation in SA for the degree of dementia present and the level of incapacitated decision-making that may be at play.

Ethically, an appointee should only make decisions on behalf of the person when absolutely necessary, and when doing so, should 
aim to act in assistance rather than in totality through offering the least restrictive option. ${ }^{[8,10,28,29,32]}$ This is also a legal requirement when considering the rights of older persons outlined in the Older Person's Act, section 9b, which promotes 'the participation of older persons at all levels' when considering the creation of a supportive environment. ${ }^{[22]}$ The reality is that often all decisionmaking power may in practical terms be taken away. ${ }^{[8]}$ While a status of incompetency may be challenged with the assistance of a medical practitioner, ${ }^{[29]}$ as documented in popular media (for example, the recent case of Britney Spears's conservatorship $\left.{ }^{[33]}\right)$, the rate and frequency at which this happens in SA is not available.

\section{Implications of curatorship for healthcare practitioners}

Apart from the implications for the person placed under curatorship, the psychiatrist who has made the request for the report and the psychologist conducting the neuropsychological assessment and either writing or supervising the report need to be cognisant of multiple practical issues.

First, the legal term 'competency' in relation to the medical or mental health practitioner is not well defined. ${ }^{[17]}$ 'Competency' of the practitioner is ultimately variably self-defined, gained through individual training and experience. ${ }^{[17,34]}$ Competency is important, as the experience of the practitioner or supervisor is likely to ensure the integrity of the assessment process and report. ${ }^{[34]}$ Problems may arise when a clinician overly relies on their individual judgement (which may be driven by their personal values), or clinical intuition, which is sometimes the case. ${ }^{[34,35]}$

Second, while it is considered best practice for the assessment and its scope to be guided via direction of the court, ${ }^{[1]}$ it may also happen at a practitioner's initiative. It is reported in a systematic review that clinicians may disagree on the diagnosis up to $29 \%$ of the time, ${ }^{[29]}$ complicated by the fact that there is no legal note of a clear cut-off point for the severity of the mental illness or the 'moment' at which a person becomes incompetent. ${ }^{[8]}$ Incapacity may also occur in different domains and contexts, making it more difficult to discern or comment on a person's overall functioning. ${ }^{[7,10]}$ For example, Kaufmann ${ }^{[7]}$ describes a case in which four practitioners came to four different conclusions regarding the individual's capacity.

Within this context, potential ethical transgressions may occur, placing a practitioner's professional registration and the reputation of the profession at stake. An example is how the assessment process may itself infringe on the vulnerability of the person, via inadequate regard for either consent or the limits of confidentiality. ${ }^{[13,36]}$ For example, in inpatient settings, a person may feel that they have limited autonomy to refuse an assessment, and feel coerced by either family or clinicians who inform them of the importance of testing. Unfamiliarity with assessment procedures or the presence of a dementing process may exclude full understanding of the consequences of the assessment, or the limitations of confidentiality.

Additionally, during the process of curator appointment, McSwiggon et al. ${ }^{[29]}$ indicated that international studies show that patients appear in court less than $57 \%$ of the time. While there may be instances in which this protects the patient's vulnerability, in other instances it may be exclusionary and impinge on the person's ability to express their wishes. Considering the expressed wishes of the person undergoing the assessment is a common recommendation. ${ }^{[10,29]}$ If this international statistic reflects practice in SA, this could violate section $9 \mathrm{~b}$ of the Older Person's Act, ${ }^{[22]}$ referred to above, as well as sections $5(2) \mathrm{b}$ and $\mathrm{c}$, in which respect for dignity is stipulated alongside a mandate for fair and equitable treatment. To the authors' knowledge, there are no known statistics capturing the presence of older persons at court curatorship proceedings in SA.

\section{The role of neuropsychology}

Neuropsychological assessment is considered an effective tool for the diagnosis of both mild and moderate neurocognitive disorders. ${ }^{[16,37-40]}$ It is a reliable diagnostic and prognostic indicator when used alongside other assessment measures such as functional ability assessments (e.g. the Vinelands Adaptive Behaviour Scales). ${ }^{[35]}$ Certain batteries of tests are thought to be able to predict functioning. ${ }^{[38]}$ Significantly, a recent study found that in SA, cognitive and neuropsychological testing does hold promise in making a diagnosis of dementia, despite cultural obstacles. ${ }^{[40]}$

A neuropsychological assessment process, when conducted thoughtfully and thoroughly, may assist in validating clinical opinions and reliably indicate a patient's level of cognitive functioning. ${ }^{[41]}$ When adaptive measures are included, or interpreted in adjunction to occupational or functional assessments, the assessment becomes useful in guiding clinical decisions regarding treatment. ${ }^{[35]}$ The issue highlighted by this article is therefore not to invalidate the use of neuropsychological assessments, or their practical advantages, but rather to interrogate their legal functionality. Precision, rigour and respect should be at the forefront of clinical practice when considering the implications outlined above.

\section{Limitations of neuropsychology}

Several limitations are noted in current neuropsychological assessment processes. These include the realities of training and testing in $\mathrm{SA},{ }^{[42,43]}$ the standards and nature of report writing more generally, ${ }^{[29]}$ and the controversy regarding the efficaciousness of neuropsychological tests as measures of day-to-day functioning. ${ }^{[14,29]}$

Revisiting the unstipulated parameters of practitioner 'competency', Watts and Shuttleworth-Edwards ${ }^{[43]}$ state that neuropsychological practice in South Africa is known to have variances in training, with the level of baseline competency dependent on the basic training. They describe university instruction as 'ad hoc', with a small number of experienced supervisors available. While the standards of SA neuropsychological practice have been deemed sufficient for a professional registration category to be endorsed and implemented, limitations in training of clinical psychologists and their implications for practice need due recognition. ${ }^{[43]}$ Any limitations in either training or professional practice are particularly salient for any forensic neuropsychological work when considering international standards of practice. ${ }^{[44]}$ In all cases, practitioners need to proceed with caution, with the implications for the patient borne in mind, and as neuropsychological assessment currently stands within the scope of both the clinical psychologist's and the neuropsychologist's scope of practice, the ethical issues outlined in this article are relevant to practitioners in both categories.

Regarding the standard of report writing, the data available are mostly from the USA. ${ }^{[29]}$ The data in a report (which, once submitted, becomes a legal document) generally reflect the assessment procedures undertaken, leading to a final comment on the referral question. The limited international data indicate that curatorship reports were found to be lacking in adequately detailed information, despite best practices suggesting commentary on cognitive, psychological and functional abilities constituting the minimum necessary requirements. ${ }^{[1,29]}$ It was also noted that reports often omitted the patient's values and preferences. ${ }^{[29]}$ Owing to the limitations of SA training noted above, the quality and 
standardisation of neuropsychological reports in SA are likely to be similarly variable. Of further concern, in an SA survey-based study, $20.2 \%$ of psychologists conducting neuropsychology assessments indicated that they did not receive supervision during their training. ${ }^{[42]}$

Report-writing recommendations result in a best-practice model being extensive, lengthy and complex, demanding experienced and expert practitioners or supervisors to integrate and interpret results. ${ }^{[13]}$ Ideally, reports should include baseline and longitudinal data, symptom description, a mental status examination, a clear justification for the diagnosis being made and a history of treatment, as well as prognostic information and the proposed treatment plan. ${ }^{[1]}$ Collateral interviews are key. ${ }^{[38,39]}$ Where possible, neuroimaging interpreted by other members of the disciplinary team, and notes on personality and behavioural changes, as well as the use of formalised measures of adaptive behaviour (such as the Vinelands Adaptive Behaviour Scales), ${ }^{[35]}$ should be integrated into the report. ${ }^{[29]}$ More generally, it is recommended that the process of capacity assessment should be multidisciplinary. ${ }^{[14]}$

The limitations of neuropsychological tests as predictors of functionality ${ }^{[13,45]}$ sometimes remain unacknowledged, yet the tests are still considered to support arguments for curatorship. ${ }^{[7]} \mathrm{A}$ holistic approach should be taken when evaluating competency. Acknowledgement that capacity to function in daily life is the central issue is essential. ${ }^{[1]}$ It should therefore include all aspects of functioning. A poor performance during a neuropsychological assessment does not necessitate incompetency, ${ }^{[1,2]}$ and the input of the multidisciplinary team is therefore essential. ${ }^{[14]}$

The limitations outlined above may result in ethical dilemmas or transgressions. Issues pertaining to confidentiality, consent, respect to persons (with particular risk to autonomy and integrity), preserving the best interests of the patients, and professional competency always need to be duly and thoroughly considered before a recommendation for curatorship is made or a report produced.

\section{Does cognitive fallout necessarilly lead to the need for curatorship?}

The diagnosis of dementia itself does not automatically infer total incapacitated competency of daily living, ${ }^{[12]}$ the key question asked in a curatorship application. ${ }^{[1]}$ 'The key issue is what the individuals can or cannot do versus the actual diagnosis ${ }^{[29]}$ (p. 42). A person does not have to be found mentally ill before having an interim curator appointed, as the interim curator may be appointed while the merits of the investigation are still in process (see section 60.4 of the Mental Health Care Act $\left.{ }^{[21]}\right)$. This article highlights the significance of that fact, as the mere appointment of a curator does not and should not wholly incapacitate the person's ability to make decisions. ${ }^{[8]}$ This concern aligns with the understanding of the dementing process, where the progression of the illness may be slow, non-linear and in some cases, static. ${ }^{[31]}$ The assessment or legal representative should therefore give an indication of a patient's level of competency in respect of his/her life at a particular point. A curatorship application made too early results in a grievous ethical error. It may compromise fundamental legal freedoms. The collaboration of clinicians and curators would be highly beneficial when protecting the integrity of the patient's self-governance. ${ }^{[1,2]}$

\section{Recommendations: Adherence to best- practice guidelines}

Adherence to best practices in competency evaluations is imperative. ${ }^{[12]}$ It is recommended that the final neuropsychological process and report be considered in adjunct with mental status, psychiatric evaluation, treatment considerations, and a functional assessment based on an appropriate screening tool or, preferably, a standardised test. The report itself, now a legal document, should adhere to best practices. The patient's values and preferences, as well as their current level of competency, should be recorded in the interests of fairness ${ }^{[29]}$ and considered when deciding on how comprehensive the curatorship needs to be. Variations in clinician opinions should be represented. ${ }^{[2]}$

This article concurs that assessment needs to focus on functionality. ${ }^{[2]}$ Simultaneously, assessment needs to account for transient and fluctuating mental states, and the ability of the person to communicate and express themselves both verbally and in written form, while 'allowing for eccentricities. ${ }^{\text {' } 10,29]}$ Recommendations for law reform have been made regarding enduring power of attorney, to preserve a degree of autonomy and honour preferences, in line with international practices. ${ }^{[10]}$ Current law demands that the least restrictive measures possible are imposed, ${ }^{[10]}$ and that attention to consent, assent and confidentiality constitute best principles. ${ }^{[36]}$ Beneficence is critical in every decision, and where possible, patient participation is encouraged.

\section{Conclusions}

Neuropsychological assessment remains an important component of curatorship application. However, assessment of functioning needs to be holistic and to include all areas of functioning, beyond neurocognitive domains. Over-reliance on a neuropsychological report may be a real limitation, both when it comes to confirming the diagnosis and regarding curatorship decisions. Clinicians undertaking clinical work in this area should be familiar with and adhere to best practices, ensuring multipronged assessment in every instance. The responsibility of the clinician and the multidisciplinary team is high; there is an implicit ethical mandate to provide clinical care that ensures protection of vulnerable patients.

Without following best-practice guidelines, psychologists and medical practitioners are at risk of ethical transgressions with serious implications for patient care, clinician integrity and registration, and the reputation of the profession. Despite the burden and pressures of service delivery, caution regarding the patient's best interests should take precedence in every evaluation.

\section{Declaration. None.}

\section{Acknowledgements. None.}

Author contributions. MLH: conceptualised the article and provided the article outline and structure, provided further review and editing. KLR: conducted the full literature search and wrote the body of the article.

\section{Funding. None.}

Conflicts of interest. None.

\footnotetext{
1. Demakis GJ. Neuropsychological evaluation of decision-making capacity in older adults. Psychol Inj Law 2013;6(1):41-50. https://doi.org/10.1007/s12207-013-9147-x

2. Moye J, Marson DC. Assessment of decision-making capacity in older adults: An emerging area of practice and research. J Gerontol B Psychol Sci Soc Sci 2007;62(1):3-11. https://doi.org/10.1093/ geronb/62.1.p3

World Health Organization. Aging and health. 4 October 2021. https://www.who.int/news-room/factsheets/detail/ageing-and-health (accessed 16 October 2021).

4. World Health Organization. Dementia. 2 September 2021. https://www.who.int/news-room/factsheets/detail/dementia (accessed 16 October 2021).

5. Manca R, de Marco M, Venneri A. The impact of COVID-19 infection and enforced prolonged social isolation on neuropsychiatric symptoms in older adults with and without dementia: A review. Front Psychiatry 2020;11:585540. https://doi.org/10.3389/fpsyt.2020.585540

6. World Health Organization. Dementia: A public health priority. WHO, 2012. https://apps.who.int/iris/ . World Health Organization. Dementia: A public health priority. WHO, 2012. https://apps.who.int/iris/
bitstream/handle/10665/75263/9789241564458_eng.pdf?sequence=1\&isAllowed=y (accessed 26 November 2021)
} 
7. Kaufmann PM. Neuropsychologist experts and civil capacity evaluations: Representative cases. Arch Clin Neuropsychol 2016;31(6):487-494. https://doi.org/10.1093/arclin/acw053

8. Meyer MM. Legal position of persons incapable of managing their own affairs. Department of Justice Meyer MM. Legal position of persons incapable of managing their own affairs. Department of Justice
and Constitutional Development, South Africa, Branch: Justice College. https://www.justice.gov.za/ and Constitutional Development, South Africa, Branch:

9. Babb E, Matrick A, Pollack T, Rosenthal LJ. Hospital guardianship: A quality needs assessment of . Babb E, Matrick A, Pollack T, Rosenthal LJ. Hospital guardianship: A quality needs assessment of
'unbefriended' patients who lack decisional capacity. J Acad Consult Liaison Psychiatr 2021;62(5):538545. https://doi.org/10.1016/j.jaclp.2021.04.002

10. South African Law Commission. Discussion Paper 105, Project 122: Assisted decision-making: Adults with impaired decision-making capacity. January 2004. https://www.justice.gov.za/salrc/dpapers/ dp105.pdf (accessed 8 February 2022).

11. Kotzé C, Roos JL, Ehlers R. End-of-life decision-making capacity in older people with serious mental illness. Front Psychiatry 2021;12:752897. https://doi.org/10.3389/fpsyt.2021.752897

12. Cohen D, Sepehry AA, Schultz IZ. Forensic neuropsychological aspects of competency evaluations: Financial and legal competency in older adults. Psychol Inj Law 2020;13(1):19-32. https://doi. org/10.1007/s12207-019-09364-8

13. Mullaly E, Kinsella G, Berberovic N, et al. Assessment of decision-making capacity: Exploration of common practices among neuropsychologists. Aust Psychol 2007;42(3):178-186. https://doi. org/10.1080/00050060601187142

14. Wood S, Bally K, Cabane C, et al. Decision-making capacity evaluations: The role of neuropsychological assessment from a multidisciplinary perspective. BMC Geriatr 2020;20:535. https://doi.org/10.1186/ s12877-020-01932-x

15. Costa A, Bak T, Caffarra P, et al. The need for harmonisation and innovation of neuropsychological assessment in neurodegenerative dementias in Europe: Consensus document of the Joint Program for Neurodegenerative Diseases Working Group. Alzheimers Res Ther 2017;9(1):1-5. https://doi. for Neurodegenerative Diseases
org/10.1186/s13195-017-0254-x

16. Casaletto KB, Heaton RK. Neuropsychological assessment: Past and future. J Int Neuropsychol Soc 2017;23(9-10):778-790. https://doi.org/10.1017/s1355617717001060

17. Moberg PJ, Kniele K. Evaluation of competency: Ethical considerations for neuropsychologists. Appl Neuropsychol 2006;13(2):101-114. https://doi.org/10.1207/s15324826an1302_5

18. South African Government. Constitution of the Republic of South Africa, 1996 - Chapter 2: Bill of Rights. https://www.gov.za/documents/constitution/chapter-2-bill-rights\#: : :text=Equality-,1.,of\%20 all\%20rights\%20and\%20freedoms (accessed 28 January 2022).

19. South Africa. National Health Act 61 of 2003. https://www.gov.za/sites/default/files/gcis document/201409/a61-03.pdf (accessed 8 February 2022).

20. South Africa. Health Professions Act 56 of 1974. (Act 6 of 1974). Ethical Rules of Conduct for Practitioners Registered Under the Health Professions Act, 1974. Government Gazette No. 29079:R717, 4 August 2006. http://www.sapc.org.za/sapc/wp-content/uploads/2018/01/ethical_rules_ of_conduct_2011.pdf (accessed 28 January 2022).

21. South Africa. Mental Health Care Act 17 of 2002. https://www.gov.za/sites/default/files/gcis _ document/201409/a17-02.pdf (accessed 28 January 2022).

22. South Africa. Older Person's Act 13 of 2006. https://www.justice.gov.za/legislation/acts/2006-013 olderpersons.pdf (accessed 28 January 2022).

23. South Africa. Administration of Estates Act 66 of 1965. https://www.justice.gov.za/legislation/ acts/1965-066\%20admin\%20estates.pdf (accessed 28 January 2022).

24. Health Professions Council of South Africa. Ethical guidelines for good practice in the health care professions. Booklet 1: General ethical guidelines for health care professions. https://www.hpcsa.
parice o.za/? contentId=79 (accessed 17 October 2021)

25. Health Professions Council of South Africa. Ethical guidelines for good practice in the health care professions. Booklet 3. National Patient's Rights Charter. https://www.hpcsa.co.za/?contentId=79 (accessed 17 October 2021)

26. Juta Law. Uniform Rules of Court. Updated to 26 June 2009. https://www.justice.gov.za/legislation/ rules/UniformRulesCourt[26jun2009].pdf (accessed 26 November 2021).
27. Zabow T. Wills and curators - decision-making in adults with impaired capacity. CME 2012;30(4):127130. http://cmej.org.za/index.php/cmej/article/view/2404

28. Zabow T. Competence and decision-making: Ethical and clinical psychiatric practice. S Afr J Bioeth Law 2008;1(2):61-63. https://doi.org/10.7196/SAJBL.29

29. McSwiggon S, Meares S, Porter M. Decision-making capacity evaluation in adult guardianship: A systematic review. Int Psychogeriatr 2016;28(3):373-384. https://doi.org/10.1017/S104161021500149 0. American Psychiatric Association. Diagnostic and Statistical Manual of Mental Disorders: DSM-5. 5th ed. APA, 2013.

31. Sadock BJ, Sadock VA, Ruiz P. Kaplan \& Sadock's Synopsis of Psychiatry. 11th ed., International Edition. Philadelphia: Kluwer, 2015

32. American Psychological Association Task Force on Psychological Assessment and Evaluation Guidelines. APA Guidelines for Psychological Assessment and Evaluation. March 2020. https://www. apa.org/about/policy/guidelines-psychological-assessment-evaluation.pdf (accessed 28 January 2022)

33. Levin S. Britney Spears's conservatorship terminated after nearly 14 years. Guardian, 12 Novembe 2021. https://www.theguardian.com/music/2021/nov/12/britney-spears-conservatorship-terminated (accessed 18 November 2021).

34. Hermann $\mathrm{H}$, Trachsel M, Biller-Andorno N. Physicians' personal values in determining medical decision-making capacity: A survey study. J Med Ethics 2015;41(9):739-744. https://doi.org/10.1136/ medethics-2014-102263

35. Moberg PJ, Rick JH. Decision-making capacity and competency in the elderly: A clinical and neuropsychological perspective. Neurorehabilitation 2008;23(5):403-413. https://doi.org/10.3233/ NRE-2008-23504

36. Binder LM. The patient-psychologist relationship and informed consent in neuropsychologica evaluations. Clin Neuropsychol 2019;33(6):988-1015. https://doi.org/10.1080/13854046.2018.15 9816

37. Ashendorf L, Alosco ML, Bing-Canar H, et al. Clinical utility of select neuropsychological assessmen battery tests in predicting functional abilities in dementia. Arch Clin Neuropsychol 2018;33(5):530540. https://doi.org/10.1093/arclin/acx100

38. Lezak MD, Howieson DB, Bigler ED, Tranel D. Neuropsychological Assessment. 5th ed. New York Oxford University Press, 2012.

39. Strauss E, Sherman EMS, Spreen O. A Compendium of Neuropsychological Tests: Administration, Norms, and Commentary. 3rd ed. New York: Oxford University Press, 2006.

40. Ramlall S, Chipps J, Bhigjee AI, Pillay BJ. Sensitivity and specificity of neuropsychological tests for dementia and mild cognitive impairment in a sample of residential elderly in South Africa. S Afr Psychiatry 2014:20(4):153-159. https://doi.org/10.4102/sajpsychiatry.v20i4.558

41. Kochhann R, Wilson MA. Introduction: Special Issue on the Neuropsychology of Aging. Psycho Neurosci 2019;12(2):141-143. https://doi.org/10.1037/pne0000176

42. Truter S, Mazabow M, Paredes AM, Rivera D, Arango-Lasprilla JC. Neuropsychology in South Africa. Appl Neuropsychol Adult 2017;25(4):344-355. https://doi.org/10.1080/23279095.2017.1301453

43. Watts AD, Shuttleworth-Edwards AB. Neuropsychology in South Africa: Confronting the challenge of specialist practice in a culturally diverse developing country. Clin Neuropsychol 2016;30(8):1305 1324. https://doi.org/10.1080/13854046.2016.1212098

44. American Psychological Association. Speciality Guidelines for Forensic Psychology. Am Psychol 2013;68(1):7-19. https://doi.org/10.1037/a0029889

45. Chaytor N, Schmitter-Edgecombe M. The ecological validity of neuropsychological tests: A review of the literature on everyday cognitive skills. Neuropsychol Rev 2003;13(4):181-197. https://doi. org/10.1023/b:nerv.0000009483.91468.fb

Accepted 29 November 2021. 